\title{
Fluoridation and cancer mortality in Anglesey
}

\author{
G WYNNE GRIFFITH
}

4 Bulkeley Terrace, Beaumaris Gwynedd

SUmmaRY Mortality in Anglesey from cancer (all sites), cancer of trachea, bronchus, and lung, cancer of stomach, and cancer of all other sites has been compared with mortality in England and Wales at two periods; 1949-53 (before fluoridation) and 1979-83 (after 20 years and more of fluoridation). No evidence has been found to support the hypothesis that water fluoridation affects cancer mortality.

Fluoridation of the public supply started in Anglesey in November 1955 following acceptance by the county council of an invitation to participate in the UK trials. ${ }^{1}$ At first, part only of the distribution was fluoridated, supplying about $40 \%$ of the population, the intention being that the rest of the county drawing water from the same source would serve as a control area. With the extension of the mains network, by the early 1960 s approximately half the population were using fluoridated water. After the publication of the first report on the trials ${ }^{2}$ the county council decided to extend the measure to the remaining areas so that by 1966 the whole population was being supplied with fluoridated water with the exception of a few isolated dwellings. Apart from short periods when the plant was out of commission for maintenance, the fluoride content has been maintained to give an overall average level of $0.9 \mathrm{ppm}$. With local government reorganisation in 1974 Anglesey lost its status as a county and became a district-officially known as Ynys Môn-within the newly formed county of Gwynedd. Being an island, no boundary changes were involved and the new district is geographically the same as the former county.

In view of the allegations, which have been given wide publicity, that fluoridation increases cancer mortality, ${ }^{3}$ the relevant data for Anglesey have been examined. Cook-Mozaffari and Doll $^{4}$ give the Anglesey SMRs for three pericensal periods 1949-53, pre-fluoridation; 1959-63 partial fluoridation; and 1969-73 when the whole water supply had been fluoridated for some years. The ratios were standardised on the rates for England and Wales 1971 and relate to all cancer, cancer of trachea, bronchus, and lung, and cancer of all other sites. For males and females (combined) the SMR for all cancer increased slightly from 90 to 92 between pericensal 1951 and 1971. Lung cancer SMR increased markedly-from 30 to 86 - while the SMR for all other cancers decreased-from 112 to 95 .

These findings can now be extended to pericensal 1981 (1979-83) when the water supply for part of the county had been fluoridated for 25 years on average, and the whole county for about 15 years. To $\omega$ supplement the information given by Cook-Mozaffari and Doll stomach cancer has been analysed separately and the residual group of all other cancers has been reduced accordingly.

\section{Method}

England and Wales rates for 1951 and 1981 have been used to calculate SMRs for 1949-53 and $1979-83$ respectively. The age groups $0-4,5-14, \ldots$. 75 years and over were used. A two-tail test of statistical significance for the difference between an SMR and 1 (the corresponding SMR of the standard population) is given by

$$
z=\frac{\text { SMR }-1}{\sqrt{\operatorname{Var} S M R+0}}
$$

Var SMR is closely approximated by $\frac{\mathrm{SMR}^{2}}{\mathrm{~N}}$ where $\mathrm{N}$ is the number of deaths. ${ }^{5}$ The results are shown in the table.

\section{Discussion}

During both periods the level of cancer mortality (all sites) did not differ significantly in either sex or in both sexes combined from the contemporaneous national level. The same is true for the residual group of all other cancers. The most remarkable change from the first period to the second is the increase relative to England and Wales from cancer of the trachea, bronchus, and lung, especially among males. 
Table 1 Standardised mortality ratios for cancer in Anglesey, 1949-53 and 1979-83

\begin{tabular}{|c|c|c|c|c|c|c|c|}
\hline Sex & Site & $S M R^{*}$ & $\mathbf{p}$ & Sex & Site & SMR* & $\mathbf{p}$ \\
\hline \multicolumn{4}{|c|}{ 1949-53 (pre-fluoridation: E\&W 1951 standard) } & \multicolumn{4}{|c|}{ 1979_83 (post-fluoridation: E\&W 1981 standard) } \\
\hline \multirow[t]{2}{*}{ Males } & All sites & $0.965(299)$ & ns & Males & All sites & $1 \cdot 034(471)$ & ns \\
\hline & $\begin{array}{l}\text { Stomach } \\
\text { Lung }^{+} \\
\text {All other sites }\end{array}$ & $\begin{array}{l}1.545(88) \\
0.548(39) \\
0.947(172)\end{array}$ & $\begin{array}{l}<0.001 \\
<0.001 \\
\text { ns }\end{array}$ & & $\begin{array}{l}\text { Stomach } \\
\text { Lung }^{+} \\
\text {All other sites }\end{array}$ & $\begin{array}{l}1 \cdot 327(55) \\
1 \cdot 013(175) \\
0.999(241)\end{array}$ & $\begin{array}{l}\text { ns } \\
\text { ns } \\
\text { ns }\end{array}$ \\
\hline \multirow[t]{2}{*}{ Females } & All sites & $1 \cdot 004(266)$ & ns & Females & All sites & $1 \cdot 015(402)$ & ns \\
\hline & $\begin{array}{l}\text { Stomach } \\
\text { Lung }^{+} \\
\text {All other sites }\end{array}$ & $\begin{array}{l}1.431(61) \\
0.768(10) \\
0.932(195)\end{array}$ & $\begin{array}{l}<0 \cdot 02 \\
\text { ns } \\
\text { ns }\end{array}$ & & $\begin{array}{l}\text { Stomach } \\
\text { Lung }{ }^{+} \\
\text {All other sites }\end{array}$ & $\begin{array}{l}1 \cdot 357(49) \\
0 \cdot 896(49) \\
1 \cdot 005(315)\end{array}$ & $\begin{array}{l}\text { ns } \\
\text { ns } \\
\text { ns }\end{array}$ \\
\hline \multirow[t]{2}{*}{ Persons } & All sites & $0.983(565)$ & ns & Persons & All sites & $1 \cdot 025(873)$ & ns \\
\hline & $\begin{array}{l}\text { Stomach } \\
\text { Lung }^{\dagger} \\
\text { All other sites }\end{array}$ & $\begin{array}{l}1.496(149) \\
0.582(49) \\
0.939(367) \\
\end{array}$ & $\begin{array}{l}<0.001 \\
<0.001 \\
\text { ns }\end{array}$ & & $\begin{array}{l}\text { Stomach } \\
\text { Lung }^{\dagger} \\
\text { All other sites }\end{array}$ & $\begin{array}{l}1.339(93) \\
0.985(224) \\
1.002(556)\end{array}$ & $\begin{array}{l}<0 \cdot 02 \\
\text { ns } \\
\text { ns }\end{array}$ \\
\hline
\end{tabular}

*Numbers of deaths in parenthesis. +Trachea, bronchus, and lung. $n s=p>0.05$

Whereas during 1949-53 there was a highly significant deficit in lung cancer deaths, this had disappeared by 1979-83. In this respect the experience of Anglesey, a rural county, conforms to that of rural areas generally. Data for pericensal 1981 for the whole country are not yet available, but the SMR for lung cancer among males in rural Wales (Wales II) had already increased from 0.59 to 0.82 between 1951 and $1971 .^{67}$ Cancer of the stomach showed an excess mortality in both sexes during the earlier period. The SMRs were lower in the second period though still significantly above the national level if the sexes are combined.

Whereas comparisons of SMRs with the standard at any given period are valid, comparisons between two SMRs are not unless both have a common standard. ${ }^{5}$ It is not possible therefore to say whether the difference in the Anglesey SMRs for stomach cancer pre- and post-fluoridation is statistically significant. It has been recognised that stomach cancer mortality was unduly high in north-west Wales, including Anglesey, at least from the $1920 \mathrm{~s}^{8}$ so that the high SMRs in 1949-53 were to be expected. Mortality from this form of malignant disease has been declining in the country generally for several decades, but it appears that the decline in Anglesey may well have been greater than in England and Wales. This is of interest because stomach cancer levels have been reported to be high in some natural fluoride areas. ${ }^{910}$ In the United States, where the downward trend in stomach cancer mortality started earlier than in most western populations including Britain, there is no sign of the decline having been arrested as fluoridation was being adopted on an increasing scale from the early $1950 \mathrm{~s}$. The age-adjusted death rate for white males, for example, declined by $51 \%$ in the United States between 1950 and 1967, whereas the male rate in England and Wales fell by only $22 \%$ over the same interval. ${ }^{11}$ Mortality from cancer of all other sites did not differ significantly in either sex in Anglesey from the contemporaneous levels in the country generally.

The increase in the numbers of cancer deaths (from 565 in $1949-53$ to 873 in 1979-83) reflects the demographic changes that have affected the county. The population increased from 50800 in 1951 to 66500 in 1981. Part of the difference of 15700 could be due to natural increase (cumulated excess births over deaths) but most of it must be attributed to net inward migration. The past 30 years have seen an increasing number of elderly persons moving to Anglesey on retirement, coming mostly from Lancashire and the Midlands. As a result of this differential migration the proportion of the local population aged 65 years and over increased by $44 \%$ compared with an increase of $29 \%$ in the numbers under 65 years. An unknown number of these new elderly residents would already have been treated for cancer while others would, so to speak, be "incubating" malignant disease; a fatal outcome in both these groups could not be attributed to fluoridation. Consequently, as an indication of a possible risk of cancer death from fluoridation, mortality levels in Anglesey (1979-83) are inflated to an unknown degree, especially perhaps for lung cancer and the remainder group. Davies ${ }^{12}$ has reported on cancer mortality in Gwynedd during 1979-83, comparing the levels in the five county districts. While the mortality from all cancer (both sexes combined) in Ynys Môn did not differ significantly from those in three of the other districts, there was a highly significant $(\mathrm{p}<0 \cdot 001)$ excess death 
rate in the county district nearest to Anglesey-Arfon, where water supplies are not fluoridated-over the level in Ynys Môn.

Three authoritative pronouncements bearing on the "fluoride-cancer link" have appeared recently, one by a distinguished jurist and the other two by groups of experts on cancer and cancer statistics. Lord Jauncey, the Scottish judge who heard the case of McColl $v$ Strathclyde (1980-82) at which Burk and Yiamouiyannis testified at length, concluded that "No association between fluoridation of water supplies and increased CDRs (cancer death rates) in the consumers has been demonstrated". $\mathrm{He}$ also found that no biochemical mechanism had been demonstrated whereby fluoridation was likely to cause cancer or accelerate existing disease. ${ }^{13}$ An expert group convened by the International Agency for Research on Cancer considered the epidemiological evidence for the alleged carcinogenicity of fluoride but could find "No evidence of an association between fluoride ingestion and mortality from cancer in humans."14 The most comprehensive analysis of all known epidemiological reports appears in the report of a working party under the chairmanship of Professor E G Knox. ${ }^{15}$ The evidence advanced for the existence of a "fluoride cancer link", mostly the works of Burk and Yiamouiyannis, is dissected in minute detail and found to contain "errors in data, errors in analytical technique, and errors in scientific logic". The report demonstrates convincingly how the data for the 20 US cities and for Birmingham (England), on which Burk and Yiamouiyannis had based their allegations, properly analysed showed a complete absence of any association. The report also examines critically material relating to other populations in the US and in 11 other countries. In every instance no association between water-borne fluoride and cancer could be detected. The most recent report from England by Chilvers and Conway ${ }^{16}$ is an analysis by body site of cancer mortality in 67 small areas with varying levels of fluoride in their water supplies. No evidence was found of any harmful effect.

\section{Conclusion}

It is never possible statistically to "prove" a negative proposition. Indeed, "in principle it is impossible to prove a negative with any study of finite size". ${ }^{17}$ The reports claiming that an association exists contain such a multitude of faults in the collection and analysis of data as to make the allegations untenable. On the other hand, the consistency with which negative results have emerged in different populations in several countries increases confidence that water fluoridation is unrelated to cancer mortality.

\section{References}

${ }^{1}$ Wynne Griffith G. The introduction of fluoridation in Anglesey. Health Education Journal. November 1956.

${ }^{2}$ The conduct of the fluoridation studies in the United Kingdom and the results achieved after five years. Reports on Public Health and Medical Subjects No 105. London: HMSO: 1962.

${ }^{3}$ Yiamouiyannis $\mathrm{J}$ and Burk D. Fluoridation and cancer: age-dependence of cancer mortality related to artificial fluoridation. Flouride 1977; 10: 102-23.

${ }^{4}$ Cook-Mozaffari P and Doll R. Fluoridation of water supplies and cancer mortality.II Mortality trends after fluoridation. J. Epidemiol Community Health 1981; 35: 233-8.

${ }^{5}$ Kahn HA. An introduction to epidemiologic methods. New York, Oxford: Oxford University Pres; 1983.

${ }^{6}$ Registrar General's decennial supplement, England and $\square$ N Wales 1951: Area mortality. London: HMSO, 1958. oे $N$

${ }^{7}$ OPCS: Area mortality tables England and Wales, $\mathbb{D}_{\vec{D}} \circ$ decennial supplement, 1969-1973 (microfiche tables) London: HMSO; 1979.

${ }^{8}$ Stocks P. Regional and local differences in cancer death rates. Studies on Medical and Population Subjects No. 1 London: HMSO; 1947.

${ }^{9}$ Heasman MA and Martin AE. Mortality in areas containing natural fluoride in their water supplies. Monthly Bull. Ministry of Health 1962; 21: 150-60.

${ }^{10}$ Hoover RN, McKay FW and Fraumeni JF. Fluoridated drinking water and the occurence of cancer. J. Natl Cancer Inst 1976; 57 757-68.

${ }^{11}$ Segi $\mathrm{M}$ and Kurihara M. Cancer mortality for selected sites in 24 countries: No 6, 1966-67. Nagoya: Japan Cancer Society: 1972.

${ }^{12}$ Davies DJC. Chief Administrative Medical Officer's Statistical Review 1983. Bangor: Gwynedd Health Authority, 1985.

${ }^{13}$ Jauncey (Lord). Opinion in causa McColl $v$ Strathclyde. The Court of Session, Edinburgh 1983.

${ }^{14}$ IARC monograph on the evaluation of the carcinogenic risk of chemicals to humans. 27; Lyon: IARC, 1982.

${ }^{15} \mathrm{Knox}$ EG (chairman). Fluoridation of water and cancer: $A$ review of the epidemiological evidence: Report of the working party. London: HMSO; 1985.

${ }^{16}$ Chilvers C and Conway D. Cancer mortality in England in relation to levels of naturally occurring fluoride in water supplies. J Epidemiol Community Health 1984; 39: 44-7.

${ }^{17}$ Occupational Health and Safety Administration. Federal Register 1980; 45:15 5156. 